\title{
Design schemes' universalization in calculation of daylight factor under side and roof lighting system in buildings
}

\author{
Sergey Stetsky ${ }^{1, *}$, and Kira Larionova ${ }^{1}$ \\ ${ }^{1}$ Moscow State University of Civil Engineering, 26, Yaroslavskoye shosse, 129337, Moscow, Russia
}

\begin{abstract}
The article describes the methods of contemporary daylight factor' (D.F.) design either with top or side natural lighting systems in buildings. The different methods of design, with different design formulas are based on preliminary determination of the type of lighting system used. But this division is rather conditional and not accurate. Sometimes the source of natural light (say, a window in a wall), which traditionally is judged as a source of a side light, is placed higher, than a monitor or skylight on a roof, which usually are determined as a sources of a top light. The same situation can be seen in determination of an angle of observation of a sky vault portion, observed from a design point within the premise considered. Thus, taking into account the above mentioned statements, one can assume, that with no strict division of external natural illumination under the overcast sky conditions, adopted as a basic theory in contemporary domestic «Codes and Regulations on Natural Lighting of Interiors», it is necessary to offer an universal design formula. This one should be based on standard formulas with respect to specific points, typical either to elements of window, monitor or skylight structures.
\end{abstract}

\section{Introduction}

The daylight factor (D.F.) values under any system of outdoor natural illumination (side or top ones) are being calculated in accordance with main laws of lighting research and technology theory and with use of modern domestic and foreign «Codes and Regulations» on Natural lighting of interiors. The basic law used is the «Moon and spencer law», which determines the luminance' condition of a sky vault as cloudy. The sky is in this case called an «overcast» and natural outdoor illuminator is evaluated as «diffuse». Such a conditions and requirements are adopted in majority of the leading countries, as a result of «Internal Commission on Illumination» (C.I.E.). recommendations. [1-6, 13-20].

In this case, the determination of the type of lighting system simultaneously leads, to the design' method needed. This problem in latest years is being discussed on the «Design of Buildings and Structures» Chair of Moscow State University of Civil Engineering [7- 12].

\footnotetext{
*Corresponding author: sergioni1947@gmail.com
} 


\section{Theoretical background}

Under constant size of a lighting opening (a window, a monitor or a skylight), the D.F. values changes in relation with the height of an opening' central point over a working plane' level.

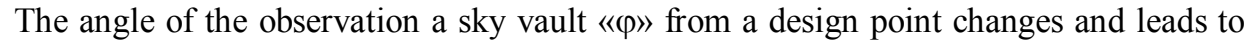
change of a «q» factor, which takes into consideration the non-uniform brightness of a sky vault. Moreover, the changes in « $\varphi$ » value leads to the change in value of «Geometric daylight factor»' values (G.D.F.) «E», due to non-uniform brightness of the standard overcast sky. All this proves the Moon-Spencer law' approving about the higher efficiency of upper parts of the sky vault in question, as compared with its low parts, but should not affect the physical sense of the design formulas 1 and 2. For side-lit premises the design formula looks like $[1,2,3,4]$ :

$$
\text { D. } F_{D} \stackrel{s}{D}=\left(\varepsilon_{S} \cdot q+\varepsilon_{B} \cdot K_{B} \cdot b_{F}\right) \cdot \frac{\tau_{T} \cdot r_{T}}{K_{S}},
$$

Where:

- D.F. $\cdot$ D - designed daylight factor for side system of natural illumination of premises;

- $\varepsilon_{\mathrm{S}}-$ geometric daylight factor, which takes into account the direct light from an overcast sky vault;

- $\mathrm{q}-\mathrm{a}$ factor, which takes into account the non-uniform brightness of an overcast sky;

- $\mathrm{K}_{\mathrm{B}}-\mathrm{a}$ factor, which takes into account a geometry of opposite-standing buildings;

- $\varepsilon_{\mathrm{B}}-$ geometric daylight factor, which takes into account the reflected light from opposite-standing buildings;

- $b_{F}-a$ factor, which takes into account the facade' brightness of the opposite-standing buildings'.

- $\mathrm{K}_{\mathrm{S}}$ - the spare factor;

- $\tau_{\mathrm{T}}-$ a total factor of light transmission through an element of side lighting system;

- $\mathrm{r}_{\mathrm{T}}-\mathrm{a}$ total factor of light reflection from a premise' surfaces.

for top-lit premises the design formula looks like:

$$
\text { D. F. }{ }_{\text {D. }}^{T}=\left[\varepsilon_{T} \cdot q+\varepsilon_{A V}\left(r_{2} \cdot K_{M, S}-1\right)\right] \cdot \frac{\tau_{T}}{K_{S}},
$$

Where:

- D.F. $\cdot \mathrm{D}-$ designed daylight factor for top system of natural illumination of interiors;

- $\varepsilon_{\mathrm{T}}-$ geometric daylight factor, which takes into account the direct light from an overcast sky vault for top system of illumination;

- $\mathrm{q}$ and $\mathrm{K}_{\mathrm{S}}$ - see note to formula (1);

- $\varepsilon_{\mathrm{AV}}-$ an average geometric daylight factor;

- $\mathrm{r}_{2}$ - a factor of light reflection from a premise' surfaces;

- $\mathrm{K}_{\mathrm{M}, \mathrm{S}}-\mathrm{a}$ factor, which takes into account a structural type of a roof' lighting element (monitor, skylight or shed);

- $\tau_{\mathrm{T}}-$ a total factor of light transmission through an elements of roof lighting system.

\section{Desk studies}

The above mentioned points are illustrated with Figures 1 and 2 and data in Table 1. According to these, it is possible to state, that one has no strict border between side and roof natural lighting of interiors. The only serious difference is that Formula 1 takes into account the lighting effect of nearby surrounding buildings, which in its pure form' is absent in 
Formula 2, but the physical sense of this effect is somehow replaced with account of « $\mathrm{K}_{\mathrm{M}, \mathrm{S}}$ » factor. For the time being, the authors of this article are trying to bridge such a gup and to elaborate the universal formula to calculate a D.F. values with respect to any system of natural lighting of interiors adopted [7, 8, 9, 10, 11, 12].

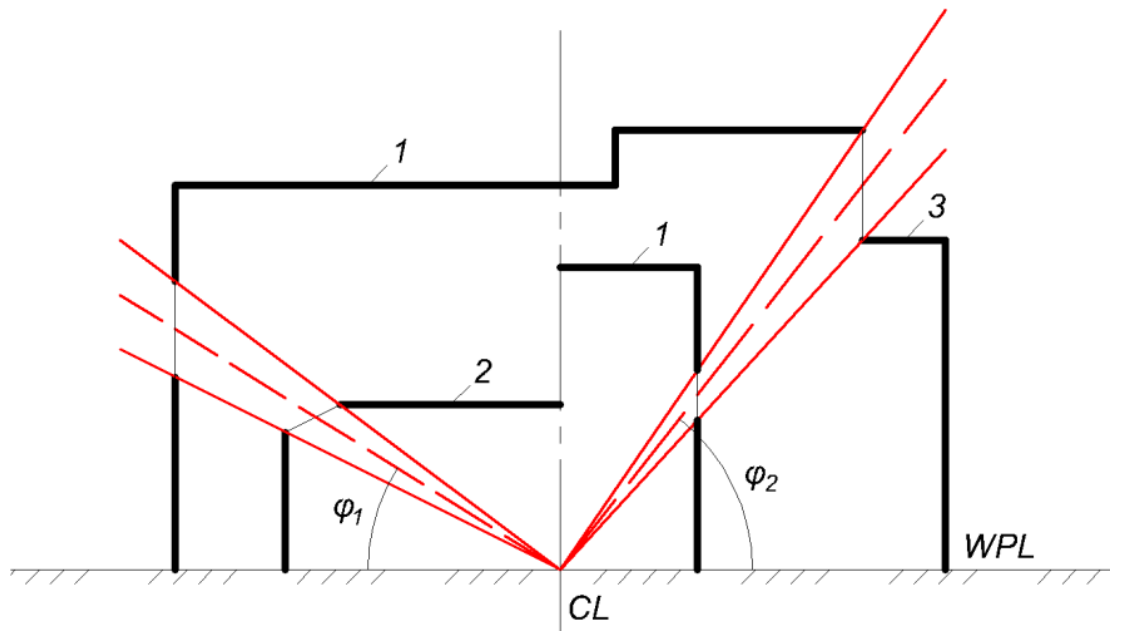

Fig. 1. Light gains to premises due to the position of windows and monitors under the different system of natural lighting in buildings.

Key:

1 - buildings with side window openings;

2 - buildings with side-top window opening;

3 - buildings with top opening in a monitor;

$\varphi_{1}, \varphi_{2}-$ angles of sky vault' observation through the openings;

$\mathrm{M}$ - design point;

C. L. - central line (axis a symmetry);

WPL - working plane' level.

Figure 1 shows the options for elements of side and roof lighting systems, which can change each other, ensuring the equal D.F. values in a premise. This statement is being confirmed with the illustration on Figure 2, which shows the light gains into a premise with different position of light openings, i.e. with different system of natural illumination of interiors under the standard overcast sky. The content of Table 1 shows the analysis of design factors, used in Formulas 1 and 2 from the point of view of their universality. The conclusions from the desk studies, resulted in number of new ideas, approaches and design methods, are presented below. 


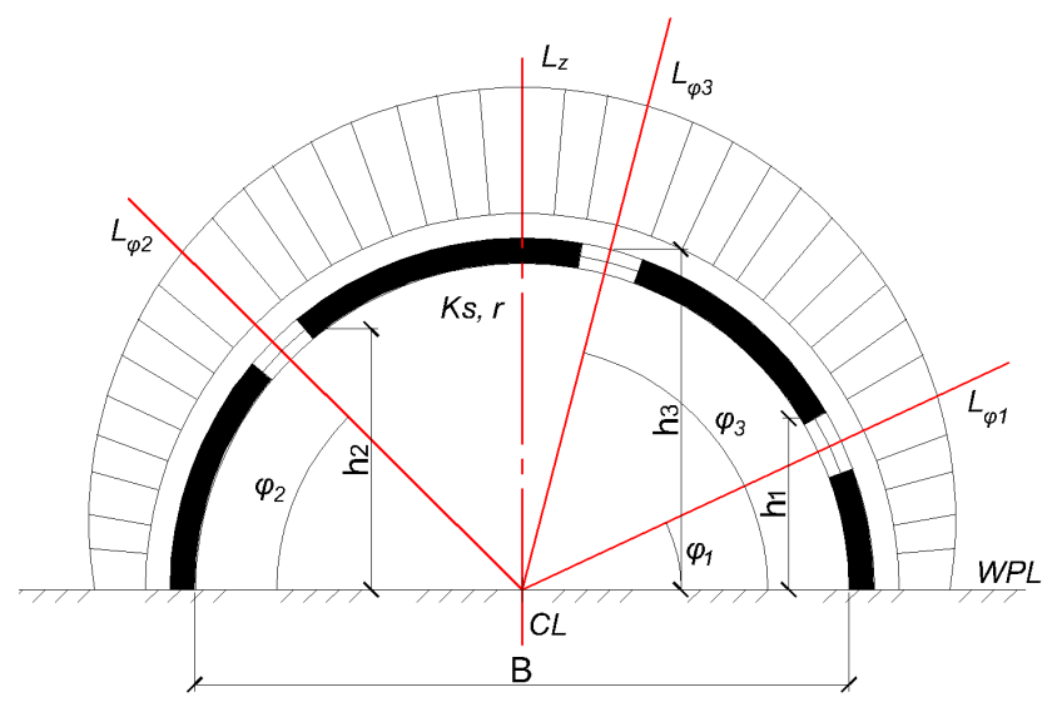

Fig. 2. Light gains to premises with different position of light openings in relation to the standard spread of brightness over the sky vault.

Key:

M, C. L. , WPL, $\varphi_{1}, \varphi_{2}, \varphi_{3}-$ see figure 1 ;

$\mathrm{t}, \mathrm{K}_{\mathrm{S}}, \mathrm{r}-$ see formulas 1 and 2 ;

$\mathrm{B}$ - the depth of a premise;

$\mathrm{h}$ - the height of a window' top over the working plane' level;

$\mathrm{L}_{\mathrm{Z}}, \mathrm{L}_{\mathrm{H}}, \mathrm{L}_{\varphi}$ - the luminance of the sky vault in zenith, horizon and angles of sky vault' observation $\varphi$ respectively.

Note

Under system of side natural lighting the quotients «q» and «६» (see Formulas 1 and 2) have the minimum values; with system of side-top lighting they have the medium values and with system of top lighting they have the maximum values. This conclusion is evident in accordance to «Moon and Spencer» Law.

Table 1. The analysis of specific design factors (quotients) universality (according formulas 1 and 2).

\begin{tabular}{|c|c|}
\hline Design factors & The degree of design factors' universality \\
\hline Specific factor «q $»$ & \multirow{3}{*}{$\begin{array}{l}\text { Possesses an absolute universality. Used in a daylight factor' design under } \\
\text { systems of side and top natural lighting of interiors }\end{array}$} \\
\hline Specific factor $\left\langle\tau_{G}\right\rangle$ & \\
\hline Specific factor $\left\langle\mathrm{K}_{\mathrm{S}} »\right.$ & \\
\hline $\begin{array}{l}\text { Specific factor } \\
\ll \mathrm{r}_{\mathrm{G}} \text { and } \mathrm{r}_{2} »\end{array}$ & $\begin{array}{l}\text { These factor are analogues in physical sense, but used in daylight factor' } \\
\text { calculations either under side or top systems of natural lighting of interiors }\end{array}$ \\
\hline $\begin{array}{l}\text { Specific factor } \\
\ll \mathrm{K}_{\mathrm{M}, \mathrm{S}} 》\end{array}$ & 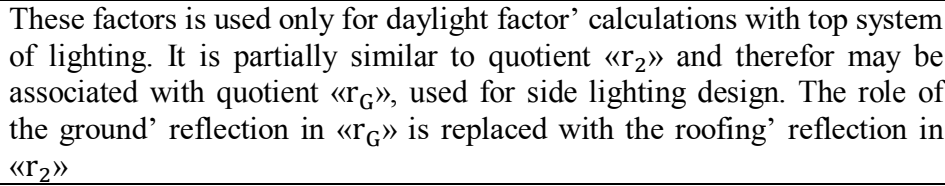 \\
\hline $\begin{array}{l}\text { Specific factor } \\
\ll \mathrm{b}_{\mathrm{F}} \text { and } \mathrm{K}_{\mathrm{B}} »\end{array}$ & $\begin{array}{l}\text { These factors is use, according to the contemporary «Codes and } \\
\text { Regulations» only for design of a daylight factor with side lighting system } \\
\text { of premises. However, the proves universality of lighting environment } \\
\text { makes it possible to use them with system of top lighting in the case of } \\
\text { implementation of skylights or monitors in deepened buildings, } \\
\text { surrounded with high-rise buildings }\end{array}$ \\
\hline
\end{tabular}




\section{Conclusions}

1. Authors of the studies in question offered the new design hypothesis, which said, that under the universal spread of light in outdoor environment, the spread of light flows in interiors of buildings must be an universal, too. Such a spread does not depend on lighting system adopted in a building, since the physical character of it remains the same and is only taken into account by the number of design factors, which characterize the specific features of a premise (present of monitors, skylights, windows or oppositestandings. Buildings, etc.).

2. It was shown, that the most important specific factor, which highly influenced the D.F.' values in a premise, was the «q" factor, which depended on angle of observation of a standard overcast sky from a design point. In this case the terms «side» or «roof» lighting systems had no sense, as far the lighting system in a building became universal. Hence, the offering of a new universal formula for all the cases of lighting system became essential and this must affected the main concepts of «Codes and Regulation» on Natural Lighting.

\section{References}

1. Codes and Regulation (SNIP) II-4-79 (Stroyizdat, Moscow, 1980)

2. Codes and Regulation (SNIP) 23-05-95* (Gosstroy of Russia, Moscow, 2005)

3. Set of Rules (SP) 23-102-2003 (Gosstroy of Russia, Moscow, 2005)

4. Set of Rules (SP) 52.13330.2011 (Minregion of Russia, Moscow, 2011)

5. N.M. Gusev, Fundamentals of Building Physics (Stroyizdat, Moscow, 1975)

6. A.K. Soloviev, Physics of the Environment (ASX Edition, Moscow, 2008)

7. S.V. Stetsky, K.O. Larionova, MGSU Gerald 12 (2014)

8. S.V. Stetsky, K.O. Larionova, Industrial and civil construction (PGS) 3 (2015)

9. S.V. Stetsky, K.O. Larionova, MGSU Gerald 9 (2012)

10. K.O. Larionova, Scientific Review 13 (2015)

11. K.O. Larionova, Scientific review 15 (2016)

12. K.O. Larionova, Scientific review 21 (2016)

13. V.M. Slukin, L.N. Smirnov, Academic Gerald of Ural NII proect of RAASN 4 (2011)

14. V.M. Slukin, E.S. Simakova, Academic Gerald of Ural NII proert of RAASN 2 (2010)

15. I. Mohelnikova, Svetotechnika 3 (2008)

16. L. Brotas, M. Wilson, Svetotechnika 3 (2008)

17. L. Brotas, M. Wilson, PLEA 2006. The 23 Conference on Passive and Low Energy Architecture (Geneva, Switzerland, 2006)

18. P.R. Terenza, Lighting Research and technology 18(2) (1986)

19. P. Moon, D. Spencer, Illuminating Engineering 37 (1942)

20. D. Spencer, J. Stakutis, Journal of Franklin Institute 252(3) (1951) 